\title{
Everybody Needs Good Neighbours: Coalition Formation Influences Floater Fight Choice
}

\author{
Richard N. C. Milner
}

Evolution, Ecology and Genetics, Research School of Biology, The Australian National University, Canberra, ACT, Australia

\author{
Correspondence \\ Richard Milner, Evolution, Ecology \& Genetics, \\ Research School of Biology, The Australian \\ National University, Canberra 0200, ACT, \\ Australia \\ E-mail: richard.milner@anu.edu.au \\ Received: October 31, 2011 \\ Initial acceptance: December 4, 2011 \\ Final acceptance: December 16, 2011 \\ (J. Wright)
}

doi: 10.1111/j.1439-0310.2011.02018.x

\begin{abstract}
In territorial species, it is sometimes less costly to help a neighbour fight off an intruder than to re-establish territory boundaries with a new, potentially stronger neighbour. In fiddler crabs, a male resident will only help his neighbour if he is larger than the intruder who, in turn, is larger than the challenged neighbour. Does this influence with whom a territory-seeking male decides to fight? I show that territory-seeking males appear to choose opponents based partly on the size of the resident's nearest neighbour. By avoiding challenging resident males with larger neighbours, territory-seeking males can reduce the likelihood of initiating a fight with a resident who might gain help from his neighbour that decreases the likelihood that the intruder will win the fight.
\end{abstract}

\section{Introduction}

Differences in the resource holding potential (RHP) of opponents largely determine fight outcome (Parker 1974). However, there are factors other than RHP that also influences fight outcome such as resource value (Krebs 1982), body condition (Fitzstephens \& Getty 2000), age (Kemp 2003), energy reserves (Marden \& Waage 1990) and territorial coalitions (Detto et al. 2010).

In territorial species, it can be beneficial to help a neighbour defend its territory against intruders. By doing so, a resident removes the cost of having to re-establish territory boundaries with a new male neighbour that is on average likely to be larger and stronger than the former neighbour. Such defensive coalitions have now been reported in a bird species (Arthus petrosus, Elfstrom 1997) and three fiddler crabs (Uca mjoebergi, U. annulipes and U.elegans; Backwell \& Jennions 2004; Booksmythe et al. 2010; Detto et al. 2010; Milner et al. 2010a). In each case, in fiddler crabs, a resident male left his own territory to help a neighbouring male (or female) fight off an intruding, territory-seeking male. However, the male only helped if he was larger than the intruding male who, in turn, was larger than the assisted, neighbouring male (Backwell \& Jennions 2004; Detto et al. 2010). This suggests that males make judicious size-based decisions about when to help. Furthermore, it suggests they can determine the size of an intruding male relative to themselves and their neighbour.

In fiddler crabs, territory-seeking males frequently bypass and avoid fighting resident males of contestable size (i.e. slightly smaller than themselves; Morrell et al. 2005). Fight outcome in fiddler crabs is largely determined by major claw size, and to overcome an ownership advantage, territory-seeking males often approach and fight resident males that are slightly smaller than themselves (Jennions \& Backwell 1996; Morrell et al. 2005; Fayed et al. 2008). Although this can explain why territory-seeking males avoid fighting resident males slightly larger than themselves, it does not explain why territoryseeking males avoid and bypass fighting resident males of an apparently contestable size.

While we now have a relatively good understanding of when and how territorial coalition arise in fiddler crabs (Detto et al. 2010), it is only recently that we have begun to explore the subsequent selective 
pressures imposed by the formation of territorial coalitions. Recently Milner et al. (2011) showed that the formation of defensive coalitions in the fiddler crab U. mjoebergi could strongly influence whom territory-seeking male choose to fight. Neighbour size appears to strongly influence whether or not a territory-seeking male initiated a fight with a resident male because burrowless males tend to avoid otherwise suitable opponents if they have large neighbours. This is a fine scale level of adaptation so it is important to test the generality of this finding, both to confirm the validity of the earlier study and to test whether the same behavioural adaptation occurs in other species. Because of publication bias, there is currently a growing concern over the lack of replicate studies testing the generality of findings both within and across taxa (Jennions \& Møller 2002; Kelly 2006). By ignoring replicate studies and tests of biological generalizations, we greatly hinder our ability to fully understand evolutionary phenomena (Kelly 2006).

Here, I investigated whether the formation of defensive coalitions in another fiddler crab species, $U$. annulipes, leads to similar tactics as those used by U. mjoebergi (Milner et al. 2011) when choosing an opponent. Specifically, I asked Whether territoryseeking males avoid challenging resident males that have neighbours larger than themselves? According to the results obtained from a previous study on the influence of neighbour size on fight choice in U. mjoebergi (Milner et al. 2011), I predict that intruding males will avoid challenging resident males that have neighbours larger than themselves.

\section{Methods}

The study was conducted on the Chukwani mudflats $\left(\mathrm{S}^{\circ} 13^{\prime} 19.37^{\prime}\right.$ E $\left.39^{\circ} 12^{\prime} 13.56^{\prime}\right)$, Zanzibar, Tanzania, from August to October 2010.

\section{Study System}

Uca annulipes occur in dense, mixed sex colonies. Both sexes defend a territory centred on a burrow (Milner et al. 2010b). Territories are uniformly distributed. Males have one greatly enlarged claw, which is used during mate attraction and as a weapon during fights with other males. Fights occur over territories, either between residents over the use of contested space at the edge of their home ranges or between a resident- and a territory-seeking male (hereafter, 'floater') for territory ownership. Burrows are a vital resource. They are the site of reproduction and provide protection from predators, desiccation and the incoming tide (Smith 8 Miller 1973; Koga et al. 2001). Furthermore, the small area of sediment surrounding the burrow is used as a source of food (Crane 1975). Males that lose their burrow, either to an intruding male or through forfeiting it to a female following mating, must quickly find a new burrow.

To determine whether a floater takes into account the size of a potential opponent's neighbour when deciding whom to fight, I monitored the fighting decisions of males in the field. To do this, I captured males, measured their major claw length (to the nearest $0.1 \mathrm{~mm}$ using dial callipers) and individually released them at least $2 \mathrm{~m}$ from their initial capture point (so that they no longer had a burrow). I then followed them until they had fought with at least two resident males. Fights were classified as any interaction, where the floater male and a resident male touched major claws. Details of the first fight were not recorded to make sure that the male had recovered from any short-term effects associated with their capture. Floater males that won their first fight with a resident male were excluded from the analysis. Following the second fight, I measured the major claw length of the challenged resident male and his nearest male neighbour $(\mathrm{n}=50)$, as well as the distance between their burrows. To provide a control, I then captured the closest male of equivalent size to the challenged resident male. I then measured the control male and his nearest male neighbour for major claw length and inter-burrow distance. Neither the control resident male nor his neighbour was ever the challenged resident male or his nearest neighbour. I used a one-way ANOVA to compare the mean claw size of the different sets of males and the population mean claw size (unpublished data, Hayes, C., Jennions, MD, Backwell, PRY). I ran pairwise multiple comparisons using a post hoc Scheffe test.

Summary statistics are presented as mean \pm SD All tests are two tailed with $\alpha=0.05$.

\section{Results}

Mean claw size differed significantly between the different groups of males (floaters, residents, neighbours, control neighbours and population mean; $\left.F_{5,384}=8.368, \quad \mathrm{p}<0.001\right)$. Floater male size $(19.38 \pm 0.55 \mathrm{~mm}, \mathrm{n}=50)$ did not significantly differ from the population mean for surface-active males $(20.33 \pm 0.39 \mathrm{~mm}, \mathrm{n}=144 ; \mathrm{p}=0.881)$. Fighting was size-assortative $(\mathrm{r}=0.429, \mathrm{p}=0.002$, 
$n=50)$. However, floater males did not fight resident males that were significantly smaller than themselves (resident: $19.53 \pm 0.61 \mathrm{~mm}, \mathrm{n}=50 ; P=$ 1). The fought resident's neighbour (16.5 \pm $0.605 \mathrm{~mm}, \mathrm{n}=50$ ) was significantly smaller than the floater male $(p=0.018)$. The control and fought resident did not differ significantly in size (control: $19.13 \pm 0.63 \mathrm{~mm}, \mathrm{n}=48 ; \quad \mathrm{p}=0.999)$, and the control resident did not differ in size from the population average $(p=0.742)$. The control neighbour $(21.11 \pm 0.55 \mathrm{~mm}, \mathrm{n}=48)$ was, however, significantly larger than the fought resident's neighbour $(\mathrm{p}<0.001)$, but not significantly different in size from the population average $(p=0.948)$ (Fig. 1).

The distance between the burrows of the opponent and his nearest neighbour $(11.6 \pm 0.4 \mathrm{~cm})$ did not significantly differ from the distance between those of the control resident and his nearest neighbour's burrow $\left(12.0 \pm 0.5 \mathrm{~cm} ; t_{45}=0.692, \mathrm{p}=0.492\right)$.

\section{Discussion}

Fighting was extremely size-assortative, with resident and floater size only differing, on average, by $0.15 \mathrm{~mm}(<1 \%)$. Unlike previous findings on fight choice in fiddler crabs (Jennions \& Backwell 1996; Morrell et al. 2005; Fayed et al. 2008; Milner et al. 2011), floater males tended to challenge resident males slightly larger than themselves. This was unexpected as floater males in the closely related fiddler crab U. mjoebergi challenge residents slightly smaller than themselves, which is suggested to occur to counteract a fighting advantage that results from burrow ownership (Fayed et al. 2008). Intriguingly, however, floater males in my study appear to choose whom to fight with based on the size of the

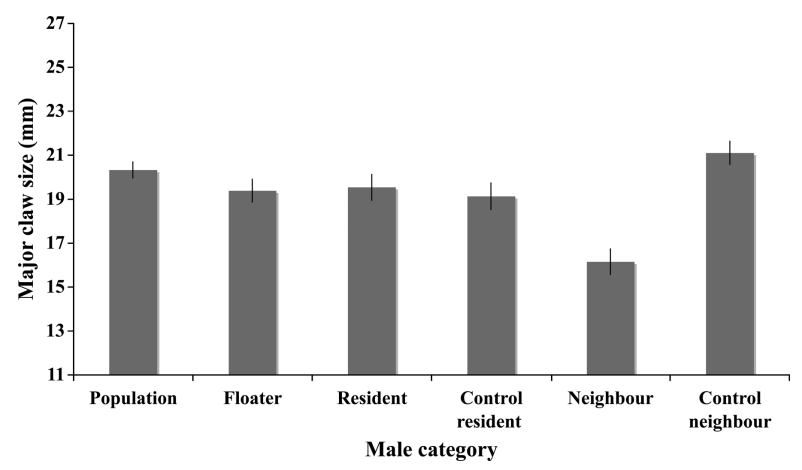

Fig. 1: Mean major claw size $(\mathrm{mm})$ of population, territory-seeking floater male, fought resident male, control resident male, fought male resident's neighbour and control male resident neighbour. Error bars indicate \pm SE of the mean. resident's nearest neighbour. Floaters chose males with neighbours substantially smaller than themselves: on average, the nearest neighbour was $\sim 15 \%$ smaller than the floater. Further, neighbours of targeted residents were $\sim 19 \%$ smaller than the population average. Therefore, floater males appear to preferentially fight resident males of approximately the same size, but only when the resident's nearest neighbour is significantly smaller.

My results are generally in agreement with an earlier study by Milner et al. (2011), showing similar fight choice decisions are made by another fiddler crab Uca mjoebergi. Like $U$. annulipes, U. mjoebergi also form territorial coalitions and it appears that the formation of such territorial coalitions places significant selective pressure on the decision-making of territory-seeking males in both species. That is, by avoiding resident males with larger neighbours, territoryseeking males can reduce the likelihood of initiating a fight with a resident who might then gain help from his neighbour. By paying attention to the size of a resident's nearest neighbour, a floater can reduce the overall costs associated with coalition fights (i.e. a greater likelihood of losing the fight when a larger helper takes over from the challenged resident). Furthermore, the fact that floating males do not target residents slightly smaller than themselves, but instead choose to fight residents with neighbours smaller than themselves, suggests that the formation of territorial coalitions (i.e. three-way fights) in $U$. annulipes is more influential than an ownership advantage in decisions regarding fight choice.

Fighting a resident with a small neighbour can have immediate benefits by increasing the likelihood of attaining a territory in the first place (Milner et al. 2011 ; this study). It might also have longer-term benefits. For instance, by obtaining a territory with a smaller neighbour, a male is effectively determining his social environment (Oh \& Badyaev 2010). This is potentially beneficial when establishing and maintaining territory boundaries because smaller male neighbours are less costly to fight (Pratt \& McLain 2006). Furthermore, a number of studies have now shown that associating with smaller, less attractive males is advantageous when attempting to attract mate-searching females (Bateson \& Healy 2005). That is, a male can increase his relative attractiveness by associating with less attractive competitors. Callander et al. (2011) have recently showed in $U$. mjobergi that there is a mating disadvantage to being surrounded by larger males. They suggested that by keeping and protecting smaller neighbours, a 
male could potentially increase his relative attractiveness to mate-searching females. The same could apply in $U$. annulipes. As demonstrated within this study, however, there are also disadvantages to associating with weaker males. By obtaining a territory with small neighbours, a male effectively removes the possibility of receiving help during an intrusion by a territory-seeking male. The fact that males still choose to fight opponents with small neighbours suggests that, given the trade-off between these two benefits, increasing the likelihood of mating is a more important determinant of fitness than improving territory retention by increasing the likelihood of receiving help from a neighbour.

\section{Acknowledgements}

I thank Patrica Backwell and Michael Jennions for their help and advice. I also thank Isobel Booksmythe, Sophia Callander, Jessica Bolton, Catherine Hayes and Melita Milner. Research was funded by an Australian Postgraduate Award (to R.N.C.M.) and the Australian Research Council (P.R.Y.B. and M.D.J.).

\section{Literature Cited}

Backwell, P. R. Y. \& Jennions, M. D. 2004: Coalition among male fiddler crabs. Nature 430, 417.

Bateson, M. \& Healy, S. D. 2005: Comparative evaluation and its implications for mate choice. Trends Ecol. Evol. 20, 659-664.

Booksmythe, I., Jennions, M. D. \& Backwell, P. R. Y. 2010 : Interspecific assistance: fiddler crabs help heterospecific neighbours in territory defence. Biol Lett 6, 748-750.

Callander, S., Jennions, M. D. \& Backwell, P. R. Y. 2011: Female choice over short and long distances: neighbour effects. Behav. Ecol. Sociobiol. 65, 2071-2078.

Crane, J. 1975: Fiddler Crabs of the World, Ocypodidae: Genus Uca. Princeton University Press, Princeton.

Detto, T., Jennions, M. D. \& Backwell, P. R. Y. 2010: When and why do territorial coalitions occur? Experimental evidence in a fiddler crab. Am Nat 175, E119-E125.

Elfstrom, S. T. 1997: Fighting behaviour and strategy of rock pipit, Anthus petrosus, neighbours: cooperative defence. Anim. Behav. 54, 535-542.

Fayed, S. A., Jennions, M. D. \& Backwell, P. R. Y. 2008: What factors contribute to the ownership? Biol Lett 4, 143-145.

Fitzstephens, D. M. \& Getty, T. 2000: Colour, fat and social status in male damselflies, Calopteryx maculata. Anim. Behav. 60, 851-855.
Hsu, Y. Y. \& Wolf, L. L. 2001: The winner and loser effect: what fighting behaviours are influenced? Anim. Behav. 61, 777-786.

Jennions, M. D. \& Backwell, P. R. Y. 1996: Residency and size affects fight duration and outcome in the fiddler crab Uca annulipes. Biol. J. Linn. Soc. 57, 293-306.

Jennions, M. D. \& Møller, A. P. 2002: Publication bias in ecology and evolution: an empirical assessment using the 'trim and fill' method. Biol. Rev. 77, 211-222.

Kelly, C. D. 2006: Replicating empirical research in behavioral ecology: how and why it should be done but rarely ever is. Q. Rev. Biol. 81, 221-236.

Kemp, D. J. 2003: Twilight fighting in the evening brown butterfly, Melanitis leda (L.) (Nymphalidae): age and residency effects. Behav. Ecol. Sociobiol. 54, 7-13.

Koga, T., Backwell, P. R. Y., Christy, J. H., Murai, M. \& Kasuya, E. 2001: Male-biased predation of a fiddler crab. Anim. Behav. 62, 201-207.

Krebs, J. R. 1982: Territorial behaviour in the great tit, Parus major: do residents always win? Behav. Ecol. Sociobiol. 11, 185-194.

Marden, J. H. \& Waage, J. K. 1990: Escalated damselfly territorial contests are energetic wars of attrition. Anim. Behav. 39, 954-959.

Milner, R. N. C., Jennions, M. D. \& Backwell, P. R. Y. 2010a: Safe sex: male-female coalitions and pre-copulatory mateguarding in a fiddler crab. Biol Lett 6, 180-182.

Milner, R. N. C., Booksmythe, I., Jennions, M. D. \& Backwell, P. R. Y. 2010b: The battle of the sexes? Territory acquisition and defence in male and female fiddler crabs Anim. Behav. 79, 735-738.

Milner, R. N. C., Jennions, M. D. \& Backwell, P. R. Y. 2011: Know thine enemy's neighbor: neighbor size affects floaters' choice of whom to fight. Behav. Ecol. 22, 947-950.

Morrell, L. J., Backwell, P. R. Y. \& Metcalfe, N. B. 2005: Fighting in fiddler crabs Uca mjoebergi: what determines duration. Anim. Behav. 70, 653-662.

Oh, K. P. \& Badyaev, A. V. 2010: Structure of social networks in a passerine bird: consequences for sexual selection and the evolution of mating strategies. Am Nat 176, E80-E89.

Parker, G. A. 1974: Assessment strategy and the evolution of fighting behaviour. J. Theor. Biol. 47, 223-243.

Pratt, A. E. \& McLain, D. K. 2006: How dear is my enemy: intruder-resident and resident-resident encounters in male sand fiddler crabs (Uca pugilator). Behaviour 143, 597-617.

Smith, W. K. \& Miller, P. C. 1973: The thermal ecology of two south Florida fiddler crabs: Uca rapax Smith and U. pugilator Bosc. Physiol Zool 46, 186-207. 